\title{
Site-specific glycan analysis of the SARS-CoV-2 spike
}

\author{
Yasunori Watanabe ${ }^{1,2,3 *}$, Joel D. Allen ${ }^{1 *}$, Daniel Wrapp ${ }^{4}$, Jason S. McLellan ${ }^{4}$, Max Crispin $^{1} \uparrow$ \\ ${ }^{1}$ School of Biological Sciences, University of Southampton, Southampton S017 1BJ, UK. ${ }^{2}$ Oxford Glycobiology Institute, Department of Biochemistry, University of Oxford, \\ South Parks Road, Oxford OX1 3QU, UK. ${ }^{3}$ Division of Structural Biology, University of Oxford, Wellcome Centre for Human Genetics, Oxford OX3 7BN, UK. ${ }^{4}$ Department of \\ Molecular Biosciences, The University of Texas at Austin, Austin, TX 78712, USA. \\ *These authors contributed equally to this work. †Corresponding author. Email: max.crispin@soton.ac.uk
}

The emergence of the betacoronavirus, SARS-CoV-2, the causative agent of COVID-19, represents a significant threat to global human health. Vaccine development is focused on the principal target of the humoral immune response, the spike (S) glycoprotein, which mediates cell entry and membrane fusion. SARS-CoV-2 S gene encodes $22 \mathrm{~N}$-linked glycan sequons per protomer, which likely play a role in protein folding and immune evasion. Here, using a site-specific mass spectrometric approach, we reveal the glycan structures on a recombinant SARS-CoV-2 S immunogen. This analysis enables mapping of the glycanprocessing states across the trimeric viral spike. We show how SARS-CoV-2 S glycans differ from typical host glycan processing, which may have implications in viral pathobiology and vaccine design.

Severe acute respiratory syndrome coronavirus-2 (SARS-CoV-2), the causative pathogen of COVID-19 $(1,2)$, induces fever, severe respiratory illness and pneumonia. SARS-CoV-2 utilizes an extensively glycosylated spike (S) protein that protrudes from the viral surface to bind to angiotensin-converting enzyme 2 (ACE2) to mediate host-cell entry (3). The S protein is trimeric class I fusion protein, composed of two functional subunits, responsible for receptor binding (S1 subunit) and membrane fusion (S2 subunit) $(4,5)$. Remarkably, the surface of the envelope spike is dominated by host-derived glycans with each trimer displaying $66 \mathrm{~N}$-linked glycosylation sites. The $\mathrm{S}$ protein is a key target in vaccine design efforts (6), and understanding the glycosylation of recombinant viral spikes can reveal fundamental features of viral biology and guide vaccine design strategies $(7,8)$.

Viral glycosylation has wide-ranging roles in viral pathobiology, including mediating protein folding and stability, and shaping viral tropism (9). Glycosylation sites are under selective pressure as they facilitate immune evasion by shielding specific epitopes from antibody neutralization. However, we note the low mutation rate of SARS-CoV-2, and as yet that there have been no observed mutations to Nlinked glycosylation sites (10). Surfaces with an unusually high density of glycans can also enable immune recognition $(9,11,12)$. The role of glycosylation in camouflaging immunogenic protein epitopes has been studied for other coronaviruses $(10,13,14)$. Coronaviruses form virions by budding into the lumen of endoplasmic reticulum-Golgi intermediate compartments (ERGIC) $(15,16)$. However, observations of complex-type glycans on virally derived material suggests that the viral glycoproteins are subjected to Golgi-resident processing enzymes $(13,17)$.

High viral glycan density and local protein architecture can sterically impair the glycan maturation pathway.
Impaired glycan maturation resulting in the presence of oligomannose-type glycans can be a sensitive reporter of nativelike protein architecture (8), and site-specific glycan analysis can be used to compare different immunogens and monitor manufacturing processes (18). Additionally, glycosylation can influence the trafficking of recombinant immunogen to germinal centers (19).

To resolve the site-specific glycosylation of SARS-CoV-2 S protein and visualize the distribution of glycoforms across the protein surface, we expressed and purified three biological replicates of recombinant soluble material in an identical manner to that which was used to obtain the high-resolution cryo-electron microscopy (cryo-EM) structure, albeit without glycan processing blockade using kifunensine (4). This variant of the S protein contains all 22 glycans on the SARS-CoV-2 S protein (Fig. 1A). Stabilization of the trimeric prefusion structure was achieved using the " $2 \mathrm{P}$ " stabilizing mutations (20) at residues 986 and 987, a "GSAS" substitution at the furin cleavage site (residues 682-685), and a C-terminal trimerization motif. This helps to maintain quaternary architecture during glycan processing. Prior to analysis, supernatant containing the recombinant SARS-CoV-2 S was purified by sizeexclusion chromatography ensure only native-like trimeric protein was analyzed (Fig. 1B and fig. S1). The trimeric conformation of the purified material was validated using negative-stain electron microscopy (Fig. 1C).

To determine the site-specific glycosylation of SARS-CoV-2 S, we employed trypsin, chymotrypsin, and alpha-lytic protease to generate three glycopeptide samples. These proteases were selected to generate glycopeptides that contain a single $\mathrm{N}$ linked glycan sequon. The glycopeptides were analyzed by liquid-chromatography-mass spectrometry (LC-MS), and the glycan compositions were determined for all $22 \mathrm{~N}$-linked glycan sites (Fig. 2). To convey the main processing features at 
each site, the abundances of each glycan are summed into oligomannose-, hybrid- and categories of complex-type glycosylation based on branching and fucosylation. The detailed, expanded graphs showing the diverse range of glycan compositions is presented in table S1 and fig. S2.

There are two sites on SARS-CoV-2 $\mathrm{S}$ that are principally oligomannose-type: N234 and N709. The predominant oligomannose-type glycan structure observed across the protein, with the exception of N234, is $\mathrm{Man}_{5} \mathrm{GlcNAc}_{2}$, which demonstrates that these sites are largely accessible to $\alpha 1,2$-mannosidases but are poor substrates for GlcNAcT-I, which is the gateway enzyme in the formation of hybrid- and complextype glycans in the Golgi apparatus. The stage at which processing is impeded is a signature related to the density and presentation of glycans on the viral spike. For example, the more densely glycosylated spikes of HIV-1 Env and Lassa virus GPC exhibit numerous sites dominated by $\mathrm{Man}_{9} \mathrm{GlcNAc}_{2}$ $(21-24)$.

A mixture of oligomannose- and complex-type glycans can be found at sites N61, N122, N603, N717, N801 and N1074 (Fig. 2 ). Of the 22 sites on the $S$ protein, 8 contain significant populations of oligomannose-type glycans, highlighting how the processing of the SARS-CoV-2 S glycans is divergent from host glycoproteins (25). The remaining 14 sites are dominated by processed, complex-type glycans.

Although unoccupied glycosylation sites were detected on SARS-CoV-2 S, when quantified they were revealed to form a very minor component of the total peptide pool (table S2). In HIV-1 immunogen research, the holes generated by unoccupied glycan sites have been shown to be immunogenic and potentially give rise to distracting epitopes (26). The high occupancy of N-linked glycan sequons of SARS-CoV-2 S indicates that recombinant immunogens will not require further optimization to enhance site occupancy.

Using the cryo-EM structure of the trimeric SARS-CoV-2 $\mathrm{S}$ protein (PDB ID 6VSB) (4), we mapped the glycosylation status of the coronavirus spike mimetic onto the experimentally determined 3D structure (Fig. 3). This combined mass spectrometric and cryo-EM analysis reveals how the N-linked glycans occlude distinct regions across the surface of the SARS-CoV-2 spike.

Shielding of the receptor binding sites on the SARS-CoV-2 spike by proximal glycosylation sites (N165, N234, N343) can be observed, especially when the receptor binding domain is in the "down" conformation. The shielding of receptor binding sites by glycans is a common feature of viral glycoproteins, as observed on SARS-CoV-1 S (10, 13), HIV-1 Env (27), influenza HA $(28,29)$, and LASV GPC (24). Given the functional constraints of receptor binding sites and the resulting low mutation rates of these residues, it is likely that there is selective pressure to utilize N-linked glycans to camouflage one of the most conserved and potentially vulnerable areas of their respective glycoproteins $(30,31)$.

It is interesting to note the dispersion of oligomannosetype glycans across both the S1 and S2 subunits. This is in contrast to other viral glycoproteins, for example the dense glycan clusters in several strains of HIV-1 Env induce oligomannose-type glycans that are recognized by antibodies (32, 33). In SARS-CoV-2 S the oligomannose-type structures are likely protected by the protein component, as exemplified by the N234 glycan which is partially sandwiched between the $\mathrm{N}$-terminal and receptor-binding domains (Fig. 3).

We characterized the N-linked glycans on extended flexible loop structures (N74 and N149) and at the membraneproximal C terminus (N1158, N1173, N1194) that were not resolved in the cryo-EM maps (4) These were determined to be complex-type glycans, consistent with steric accessibility of these residues.

While the oligomannose-type glycan content (28\%) (table S2) is above that observed on typical host glycoproteins, it is lower than other viral glycoproteins. For example, one of the most densely glycosylated viral spike proteins is HIV-1 Env, which exhibits $\sim 60 \%$ oligomannose-type glycans $(21,34)$. This suggests that SARS-CoV-2 S protein is less densely glycosylated and that the glycans form less of a shield compared with other viral glycoproteins including HIV-1 Env and LASV GPC, which may be beneficial for the elicitation of neutralizing antibodies.

Additionally, the processing of complex-type glycans is an important consideration in immunogen engineering, especially considering that epitopes of neutralizing antibodies against SARS-CoV-2 S can contain fucosylated glycans at N343 (35). Across the $22 \mathrm{~N}$-linked glycosylation sites, $52 \%$ are fucosylated and $15 \%$ of the glycans contain at least one sialic acid residue (table S2 and fig. S3). Our analysis reveals that N343 is highly fucosylated with $98 \%$ of detected glycans bearing fucose residues. Glycan modifications can be heavily influenced by the cellular expression system utilized. We have previously demonstrated for HIV-1 Env glycosylation that the processing of complex-type glycans is driven by the producer cell but that the levels of oligomannose-type glycans were largely independent of the expression system and is much more closely related to the protein structure and glycan density (36).

Highly dense glycan shields, such as those observed on LASV GPC and HIV-1 Env, feature so-called mannose clusters $(22,24)$ on the protein surface (Fig. 4). While small mannosetype clusters have been characterized on the S1 subunit of Middle East respiratory syndrome (MERS) CoV S (10), no such phenomenon has been observed for SARS-CoV-1 or SARS-CoV-2 S proteins. The site-specific glycosylation analysis reported here suggests that the glycan shield of SARSCoV-2 S is consistent with other coronaviruses and similarly exhibits numerous vulnerabilities throughout the glycan 
shield (10). Finally, we detected trace levels of O-linked glycosylation at T323/S325 with over $99 \%$ of these sites unmodified (fig. S4) suggesting that O-linked glycosylation of this region is minimal when the structure is native-like.

Our glycosylation analysis of SARS-CoV-2 offers a detailed benchmark of site-specific glycan signatures characteristic of a natively folded trimeric spike. As an increasing number of glycoprotein-based vaccine candidates are being developed, their detailed glycan analysis offers a route for comparing immunogen integrity and will also be important to monitor as manufacturing processes are scaled for clinical use. Glycan profiling will therefore also be an important measure of antigen quality in the manufacture of serological testing kits. Finally, with the advent of nucleotide-based vaccines, it will be important to understand how those delivery mechanisms impact immunogen processing and presentation.

\section{REFERENCES AND NOTES}

1. C. Huang, Y. Wang, X. Li, L. Ren, J. Zhao, Y. Hu, L. Zhang, G. Fan, J. Xu, X. Gu, Z. Cheng, T. Yu, J. Xia, Y. Wei, W. Wu, X. Xie, W. Yin, H. Li, M. Liu, Y. Xiao, H. Gao, L. Guo, J. Xie, G. Wang, R. Jiang, Z. Gao, Q. Jin, J. Wang, B. Cao, Clinical features of patients infected with 2019 novel coronavirus in Wuhan, China. Lancet 395, 497506 (2020). doi:10.1016/S0140-6736(20)30183-5 Medline

2. X. Yang, Y. Yu, J. Xu, H. Shu, J. Xia, H. Liu, Y. Wu, L. Zhang, Z. Yu, M. Fang, T. Yu, Y. Wang, S. Pan, X. Zou, S. Yuan, Y. Shang, Clinical course and outcomes of critically ill patients with SARS-CoV-2 pneumonia in Wuhan, China: a single-centered, retrospective, observational study. Lancet Respir. Med. 10.1016/S22132600(20)30079-5 (2020)

3. M. Letko, A. Marzi, V. Munster, Functional assessment of cell entry and receptor usage for SARS-CoV-2 and other lineage B betacoronaviruses. Nat. Microbiol. 5, 562-569 (2020). doi:10.1038/s41564-020-0688-y Medline

4. D. Wrapp, N. Wang, K. S. Corbett, J. A. Goldsmith, C. L. Hsieh, O. Abiona, B. S. Graham, J. S. McLellan, Cryo-EM structure of the 2019-nCoV spike in the prefusion conformation. Science 367, 1260-1263 (2020). 10.1126/science.abb2507 Medline

5. A. C. Walls, Y. J. Park, M. A. Tortorici, A. Wall, A. T. McGuire, D. Veesler, Structure, function, and antigenicity of the SARS-CoV-2 spike glycoprotein. Cell 181, 281292.e6 (2020). 10.1016/i.cell.2020.02.058 Medline

6. F. Amanat, F. Krammer, SARS-CoV-2 vaccines: Status report. Immunity 52, 583589 (2020). doi:10.1016/i.immuni.2020.03.007 Medline

7. L. Cao, J. K. Diedrich, D. W. Kulp, M. Pauthner, L. He, S. R. Park, D. Sok, C. Y. Su, C. M. Delahunty, S. Menis, R. Andrabi, J. Guenaga, E. Georgeson, M. Kubitz, Y. Adachi, D. R. Burton, W. R. Schief, J. R. Yates III, J. C. Paulson, Global site-specific $\mathrm{N}$-glycosylation analysis of HIV envelope glycoprotein. Nat. Commun. 8, 14954 (2017). doi:10.1038/ncomms14954 Medline

8. A.-J. Behrens, D. J. Harvey, E. Milne, A. Cupo, A. Kumar, N. Zitzmann, W. B. Struwe, J. P. Moore, M. Crispin, Molecular architecture of the cleavage-dependent mannose patch on a soluble HIV-1 envelope glycoprotein trimer. J. Virol. 91, e01894-e16 (2017). Medline

9. Y. Watanabe, T. A. Bowden, I. A. Wilson, M. Crispin, Exploitation of glycosylation in enveloped virus pathobiology. Biochim. Biophys. Acta 1863, 1480-1497 (2019). doi:10.1016/i.bbagen.2019.05.012 Medline

10. Y. Watanabe, Z. T. Berndsen, J. Raghwani, G. E. Seabright, J. D. Allen, J. S. McLellan, I. A. Wilson, T. A. Bowden, A. B. Ward, M. Crispin, Vulnerabilities in coronavirus glycan shields despite extensive glycosylation. bioRxiv 2020.02.20.957472 [Preprint]. $21 \quad$ February 2020. https://doi.org/10.1101/2020.02.20.957472.

11. M. Dalziel, M. Crispin, C. N. Scanlan, N. Zitzmann, R. A. Dwek, Emerging principles for the therapeutic exploitation of glycosylation. Science 343, 1235681 (2014). doi:10.1126/science.1235681 Medline
12. C. N. Scanlan, J. Offer, N. Zitzmann, R. A. Dwek, Exploiting the defensive sugars of HIV-1 for drug and vaccine design. Nature 446, 1038-1045 (2007). doi:10.1038/nature05818 Medline

13. A. C. Walls, X. Xiong, Y.-J. Park, M. A. Tortorici, J. Snijder, J. Quispe, E. Cameroni, R. Gopal, M. Dai, A. Lanzavecchia, M. Zambon, F. A. Rey, D. Corti, D. Veesler, Unexpected receptor functional mimicry elucidates activation of coronavirus fusion. Cell 176, 1026-1039.e15 (2019). doi:10.1016/i.cell.2018.12.028 Medline

14. T. J. Yang, Y.-C. Chang, T.-P. Ko, P. Draczkowski, Y.-C. Chien, Y.-C. Chang, K.-P. Wu, K.-H. Khoo, H.-W. Chang, S. D. Hsu, Cryo-EM analysis of a feline coronavirus spike protein reveals a unique structure and camouflaging glycans. Proc. Natl. Acad. Sci. U.S.A. 117, 1438-1446 (2020). doi:10.1073/pnas.1908898117 Medline

15. S. Stertz, M. Reichelt, M. Spiegel, T. Kuri, L. Martínez-Sobrido, A. García-Sastre, F. Weber, G. Kochs, The intracellular sites of early replication and budding of SARScoronavirus. Virology 361, 304-315 (2007). doi:10.1016/i.virol.2006.11.027 Medline

16. P. Venkatagopalan, S. M. Daskalova, L. A. Lopez, K. A. Dolezal, B. G. Hogue, Coronavirus envelope (E) protein remains at the site of assembly. Virology 478, 75-85 (2015). doi:10.1016/i.virol.2015.02.005 Medline

17. G. Ritchie, D. J. Harvey, F. Feldmann, U. Stroeher, H. Feldmann, L. Royle, R. A. Dwek, P. M. Rudd, Identification of $\mathrm{N}$-linked carbohydrates from severe acute respiratory syndrome (SARS) spike glycoprotein. Virology 399, 257-269 (2010). doi:10.1016/i.virol.2009.12.020 Medline

18. A. A. Hargett, M. B. Renfrow, Glycosylation of viral surface proteins probed by mass spectrometry. Curr. Opin. Virol. 36, 56-66 (2019). doi:10.1016/i.coviro.2019.05.003 Medline

19. T. Tokatlian, B. J. Read, C. A. Jones, D. W. Kulp, S. Menis, J. Y. H. Chang, J. M. Steichen, S. Kumari, J. D. Allen, E. L. Dane, A. Liguori, M. Sangesland, D. Lingwood, M. Crispin, W. R. Schief, D. J. Irvine, Innate immune recognition of glycans targets HIV nanoparticle immunogens to germinal centers. Science 363, 649-654 (2019). doi:10.1126/science.aat9120 Medline

20. J. Pallesen, N. Wang, K. S. Corbett, D. Wrapp, R. N. Kirchdoerfer, H. L. Turner, C. A. Cottrell, M. M. Becker, L. Wang, W. Shi, W.-P. Kong, E. L. Andres, A. N. Kettenbach, M. R. Denison, J. D. Chappell, B. S. Graham, A. B. Ward, J. S. McLellan, Immunogenicity and structures of a rationally designed prefusion MERS-CoV spike antigen. Proc. Natl. Acad. Sci. U.S.A. 114, E7348-E7357 (2017). doi:10.1073/pnas.1707304114 Medline

21. W. B. Struwe, E. Chertova, J. D. Allen, G. E. Seabright, Y. Watanabe, D. J. Harvey, M. Medina-Ramirez, J. D. Roser, R. Smith, D. Westcott, B. F. Keele, J. W. Bess Jr., R. W. Sanders, J. D. Lifson, J. P. Moore, M. Crispin, Site-specific glycosylation of virion-derived HIV-1 Env is mimicked by a soluble trimeric immunogen. Cell Rep. 24, 1958-1966.e5 (2018). doi:10.1016/i.celrep.2018.07.080 Medline

22. A.-J. Behrens, S. Vasiljevic, L. K. Pritchard, D. J. Harvey, R. S. Andev, S. A. Krumm, W. B. Struwe, A. Cupo, A. Kumar, N. Zitzmann, G. E. Seabright, H. B. Kramer, D. I. R. Spencer, L. Royle, J. H. Lee, P. J. Klasse, D. R. Burton, I. A. Wilson, A. B. Ward, R. W. Sanders, J. P. Moore, K. J. Doores, M. Crispin, Composition and antigenic effects of individual glycan sites of a trimeric HIV-1 envelope glycoprotein. Cell Rep. 14, 2695-2706 (2016). doi:10.1016/j.celrep.2016.02.058 Medline

23. M. Panico, L. Bouché, D. Binet, M.-J. O'Connor, D. Rahman, P.-C. Pang, K. Canis, S. J. North, R. C. Desrosiers, E. Chertova, B. F. Keele, J. W. Bess Jr., J. D. Lifson, S. M. Haslam, A. Dell, H. R. Morris, Mapping the complete glycoproteome of virionderived HIV-1 gp120 provides insights into broadly neutralizing antibody binding. Sci. Rep. 6, 32956 (2016). doi:10.1038/srep32956 Medline

24. Y. Watanabe, J. Raghwani, J. D. Allen, G. E. Seabright, S. Li, F. Moser, J. T. Huiskonen, T. Strecker, T. A. Bowden, M. Crispin, Structure of the Lassa virus glycan shield provides a model for immunological resistance. Proc. Natl. Acad. Sci. U.S.A. 115, 7320-7325 (2018). doi:10.1073/pnas.1803990115 Medline

25. I. Loke, D. Kolarich, N. H. Packer, M. Thaysen-Andersen, Emerging roles of protein mannosylation in inflammation and infection. Mol. Aspects Med. 51, 31-55 (2016). doi:10.1016/i.mam.2016.04.004 Medline

26. M. Bianchi, H. L. Turner, B. Nogal, C. A. Cottrell, D. Oyen, M. Pauthner, R. Bastidas, R. Nedellec, L. E. McCoy, I. A. Wilson, D. R. Burton, A. B. Ward, L. Hangartner, Electron-microscopy-based epitope mapping defines specificities of polyclonal antibodies elicited during HIV-1 BG505 envelope trimer immunization. Immunity 49, 288-300.e8 (2018). doi:10.1016/i.immuni.2018.07.009 Medline

27. J. Jardine, J.-P. Julien, S. Menis, T. Ota, O. Kalyuzhniy, A. McGuire, D. Sok, P.-S. 
Huang, S. MacPherson, M. Jones, T. Nieusma, J. Mathison, D. Baker, A. B. Ward, D. R. Burton, L. Stamatatos, D. Nemazee, I. A. Wilson, W. R. Schief, Rational HIV immunogen design to target specific germline B cell receptors. Science 340, 711716 (2013). doi:10.1126/science.1234150 Medline

28. C.-J. Wei, J. C. Boyington, K. Dai, K. V. Houser, M. B. Pearce, W. P. Kong, Z. Y. Yang, T. M. Tumpey, G. J. Nabel, Cross-neutralization of 1918 and 2009 influenza viruses: Role of glycans in viral evolution and vaccine design. Sci. Transl. Med. 2, 24ra21 (2010). Medline

29. R. Xu, D. C. Ekiert, J. C. Krause, R. Hai, J. E. Crowe Jr., I. A. Wilson, Structural basis of preexisting immunity to the $2009 \mathrm{H} 1 \mathrm{N1}$ pandemic influenza virus. Science 328 , 357-360 (2010). doi:10.1126/science.1186430 Medline

30. X. Wei, J. M. Decker, S. Wang, H. Hui, J. C. Kappes, X. Wu, J. F. Salazar-Gonzalez, M. G. Salazar, J. M. Kilby, M. S. Saag, N. L. Komarova, M. A. Nowak, B. H. Hahn, P. D. Kwong, G. M. Shaw, Antibody neutralization and escape by HIV-1. Nature 422 , 307-312 (2003). doi:10.1038/nature01470 Medline

31. M. Zhang, B. Gaschen, W. Blay, B. Foley, N. Haigwood, C. Kuiken, B. Korber, Tracking global patterns of $\mathrm{N}$-linked glycosylation site variation in highly variable viral glycoproteins: HIV, SIV, and HCV envelopes and influenza hemagglutinin. Glycobiology 14, 1229-1246 (2004). doi:10.1093/glycob/cwh106 Medline

32. G. B. E. Stewart-Jones, C. Soto, T. Lemmin, G.-Y. Chuang, A. Druz, R. Kong, P. V. Thomas, K. Wagh, T. Zhou, A.-J. Behrens, T. Bylund, C. W. Choi, J. R. Davison, I. S. Georgiev, M. G. Joyce, Y. D. Kwon, M. Pancera, J. Taft, Y. Yang, B. Zhang, S. S. Shivatare, V. S. Shivatare, C.-C. D. Lee, C.-Y. Wu, C. A. Bewley, D. R. Burton, W. C. Koff, M. Connors, M. Crispin, U. Baxa, B. T. Korber, C.-H. Wong, J. R. Mascola, P. D. Kwong, Trimeric HIV-1-Env structures define glycan shields from clades A, B, and G. Cell 165, 813-826 (2016). doi:10.1016/i.cell.2016.04.010 Medline

33. D. Sok, K. J. Doores, B. Briney, K. M. Le, K. L. Saye-Francisco, A. Ramos, D. W. Kulp, J.-P. Julien, S. Menis, L. Wickramasinghe, M. S. Seaman, W. R. Schief, I. A. Wilson, P. Poignard, D. R. Burton, Promiscuous glycan site recognition by antibodies to the high-mannose patch of gp120 broadens neutralization of HIV. Sci. Transl. Med. 6. 236 ra63 (2014). doi:10.1126/scitransImed.3008104 Medline

34. L. Cao, M. Pauthner, R. Andrabi, K. Rantalainen, Z. Berndsen, J. K. Diedrich, S. Menis, D. Sok, R. Bastidas, S. R. Park, C. M. Delahunty, L. He, J. Guenaga, R. T. Wyatt, W. R. Schief, A. B. Ward, J. R. Yates III, D. R. Burton, J. C. Paulson, Differential processing of HIV envelope glycans on the virus and soluble recombinant trimer. Nat. Commun. 9, 3693 (2018). doi:10.1038/s41467-01806121-4 Medline

35. D. Pinto, Y.-J. Park, M. Beltramello, A. C. Walls, M. A. Tortorici, S. Bianchi, S. Jaconi, K. Culap, F. Zatta, A. De Marco, A. Peter, B. Guarino, R. Spreafico, E. Cameroni, J. B. Case, R. E. Chen, C. Havenar-Daughton, G. Snell, A. Telenti, H. W. Virgin, A. Lanzavecchia, M. S. Diamond, K. Fink, D. Veesler, D. Corti, Structural and functional analysis of a potent sarbecovirus neutralizing antibody. bioRxiv $\begin{array}{lllll}\text { 2020.04.07.023903 } & \text { [Preprint]. } & 10 & \text { April } & \end{array}$ https://doi.org/10.1101/2020.04.07.023903.

36. L. K. Pritchard, D. J. Harvey, C. Bonomelli, M. Crispin, K. J. Doores, Cell- and protein-directed glycosylation of native cleaved HIV-1 envelope. J. Virol. 89, 8932-8944 (2015). doi:10.1128/JVI.01190-15 Medline

37. M. Crispin, SARS-CoV-2 spike site-specific N-linked glycan analysis. MassIVE Database (2020); doi:10.25345/C54X4K.

38. T. Grant, A. Rohou, N. Grigorieff, cisTEM, user-friendly software for single-particle image processing. eLife 7, e35383 (2018). doi:10.7554/eLife.35383 Medline

39. P. Emsley, M. Crispin, Structural analysis of glycoproteins: Building N-linked glycans with Coot. Acta Crystallogr. D Struct. Biol. 74, 256-263 (2018). doi:10.1107/S2059798318005119 Medline

\section{ACKNOWLEDGMENTS}

We thank M. Dixon and M. Gowland-Pryde for supporting our work on this project during the difficulties arising from the pandemic, and G. Ould for critical reading of the manuscript. Funding: This work was funded by the International AIDS Vaccine Initiative, Bill and Melinda Gates Foundation through the Collaboration for AIDS Vaccine Discovery (OPP1084519 to M.C., and 1196345 to M.C.), the NIAID (R01-AI127521 to J.S.M) and the Scripps Consortium for HIV Vaccine Development (CHAVD) (Al144462 to M.C.). M.C. is a Supernumerary Fellow of Oriel College, Oxford, and Professor Adjunct at Scripps Research, CA. Author contributions: Y.W. and J.A. performed mass spectrometry experiments and analyzed data. Y.W. built glycosylated models. J.S.M. and M.C. supervised experiments. Y.W., J.A., and D.W. expressed and purified proteins. Y.W., J.A., and M.C wrote the manuscript with input from all authors. Competing interests: J.S.M. is an inventor on U.S. patent application no. 62/412,703 ("Prefusion Coronavirus Spike Proteins and Their Use"), and D.W., and J.S.M. are inventors on U.S. patent application no. 62/972,886 ("2019-nCoV Vaccine"). Data and materials availability: Mass spectrometry raw files have been deposited in the MassIVE proteomics database (37). The plasmid is available from J.S.M. under a material transfer agreement with The University of Texas at Austin. This work is licensed under a Creative Commons Attribution 4.0 International (CC BY 4.0) license, which permits unrestricted use, distribution, and reproduction in any medium, provided the original work is properly cited. To view a copy of this license, visit https://creativecommons.org/licenses/by/4.0/. This license does not apply to figures/photos/artwork or other content included in the article that is credited to a third party; obtain authorization from the rights holder before using such material.

\section{SUPPLEMENTARY MATERIALS}

science.sciencemag.org/cgi/content/full/science.abb9983/DC1

Materials and Methods

Figs. S1 to S4

Tables S1 and S2

References $(38,39)$

MDAR Reproducibility Checklist

Data S1

31 March 2020; accepted 29 April 2020

Published online 4 May 2020

10.1126/science.abb9983 

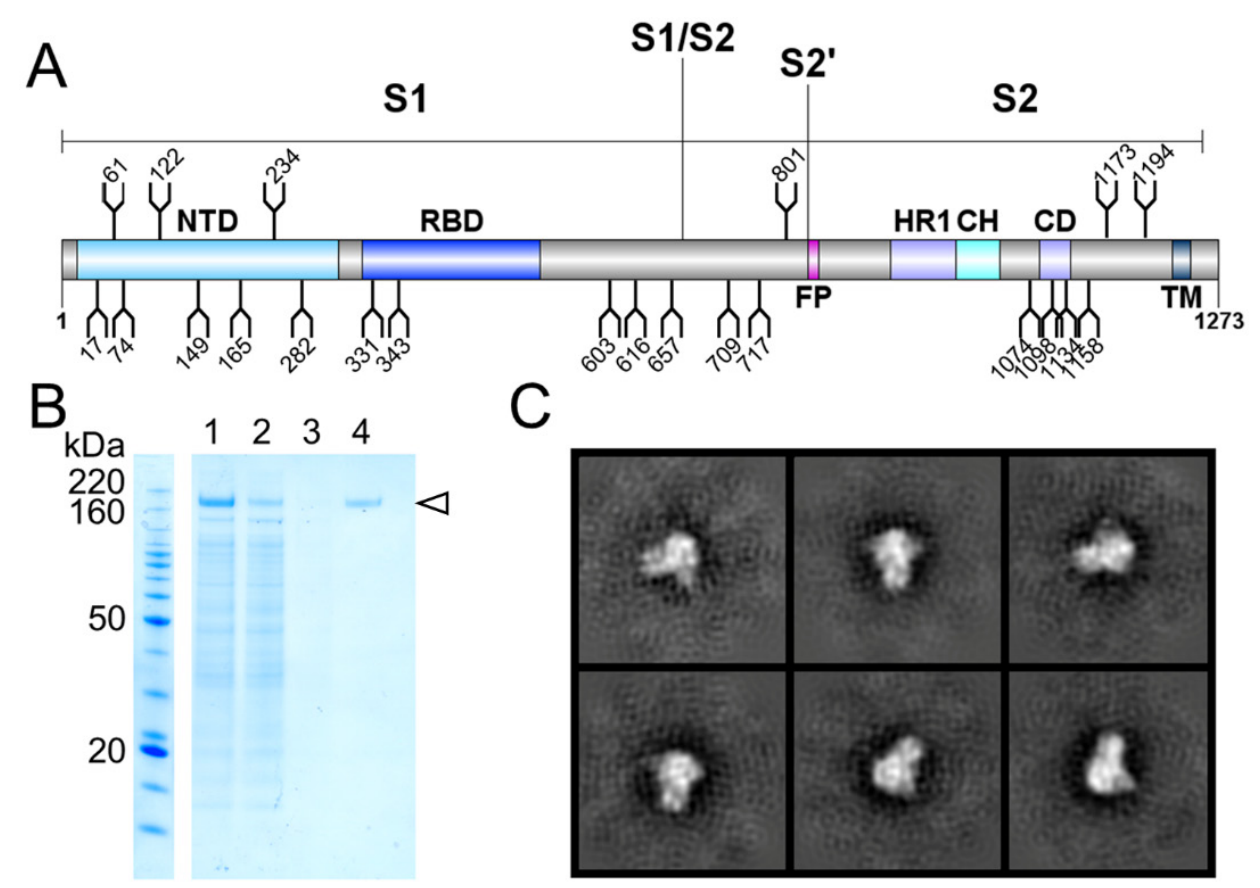

Fig. 1. Expression and validation of SARS-CoV-2 S glycoprotein. (A) Schematic representation of SARS-CoV-2 S glycoprotein. The positions of $N$-linked glycosylation sequons ( $N-X-S / T$, where $X \neq P$ ) are shown as branches. Protein domains are illustrated: $\mathrm{N}$-terminal domain (NTD), receptor-binding domain (RBD), fusion peptide (FP), heptad repeat $1(\mathrm{HR} 1)$, central helix $(\mathrm{CH})$, connector domain (CD), and transmembrane domain (TM). (B) SDS-PAGE analysis of SARS-CoV-2 S protein expressed in human embryonic kidney 293F cells. Lane 1: filtered supernatant from transfected cells; lane 2: flow-through from StrepTactin resin; lane 3: wash from StrepTactin resin; lane 4: elution from StrepTactin resin. (C) Negative-stain EM 2D class averages of the SARS-CoV-2 S protein. 2D class averages of the SARS-CoV-2 S protein are shown, confirming that the protein adopts the trimeric prefusion conformation matching the material used to determine the structure (4). 


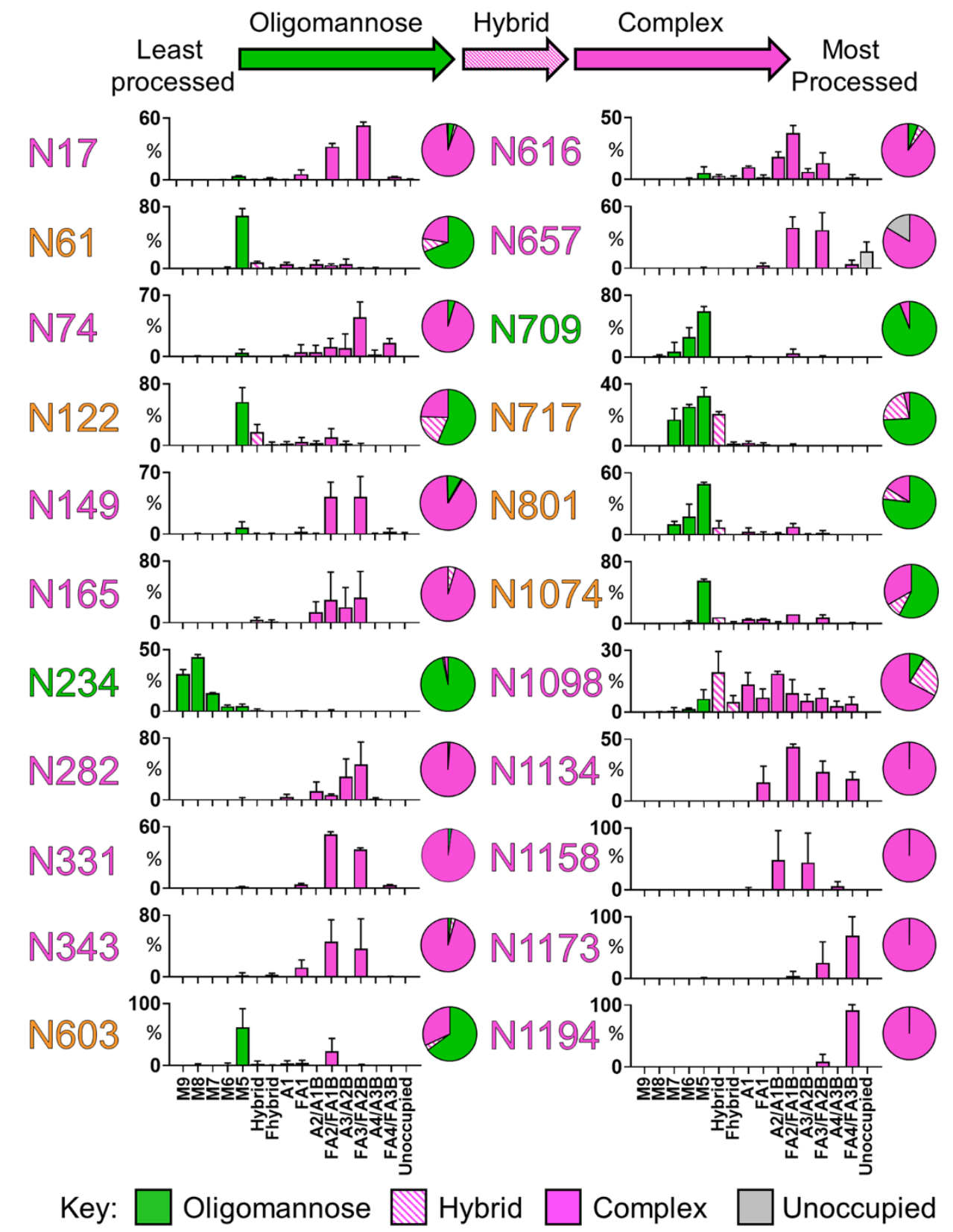

Fig. 2. Site-specific N-linked glycosylation of SARS-CoV-2 S glycoprotein. The schematic illustrates the color code for the principal glycan types that can arise along the maturation pathway from oligomannose-, hybrid- to complex-type glycans. The graphs summarize quantitative mass spectrometric analysis of the glycan population present at individual $\mathrm{N}$-linked glycosylation sites simplified into categories of glycans. The oligomannose-type glycan series (M9 to M5; Man ${ }_{9} \mathrm{GlcNAc}_{2}$ to $\mathrm{Man}_{5} \mathrm{GlCNAC}_{2}$ ) is colored green, afucosylated and fucosylated hybrid-type glycans (Hybrid \& $\mathrm{F}$ Hybrid) dashed pink, and complex glycans grouped according to the number of antennae and presence of core fucosylation (A1 to FA4) and are colored pink. Unoccupancy of an N-linked glycan site is represented in grey. The pie charts summarize the quantification of these glycans. Glycan sites are colored according to oligomannose-type glycan content with the glycan sites labeled in green (80-100\%), orange (30-79\%) and pink (0-29\%). An extended version of the site-specific analysis showing the heterogeneity within each category can be found in table S1 and fig. S2. The bar graphs represent the mean quantities of three biological replicates with error bars representing the standard error of the mean. 


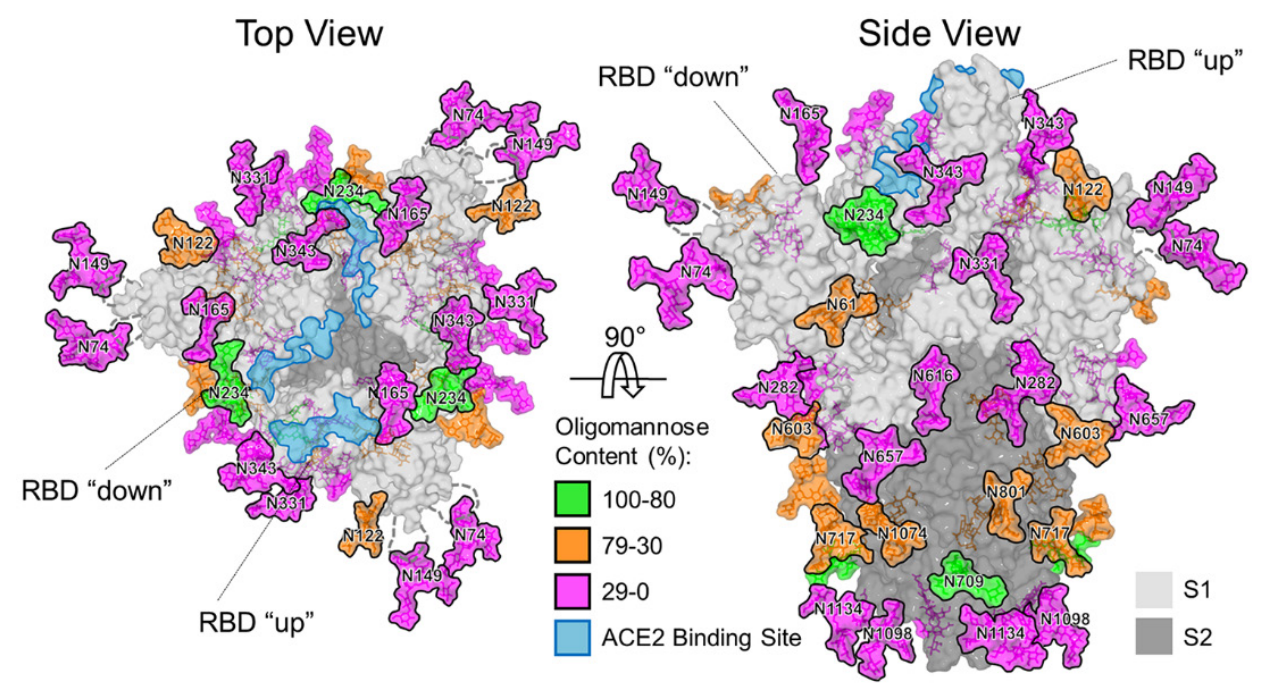

Fig. 3. Structure-based mapping of SARS-CoV-2 S N-linked glycans. Representative glycans are modeled onto the prefusion structure of trimeric SARS-CoV-2 S glycoprotein (PDB ID 6VSB) (4), with one RBD in the "up" conformation and the other two RBDs in the "down" conformation. The glycans are colored according to oligomannose content as defined by the key. ACE2 receptor binding sites are highlighted in light blue. The S1 and S2 subunits are rendered with translucent surface representation, colored light and dark grey, respectively. Note that the flexible loops on which N74 and N149 glycan sites reside are represented as dashed lines with glycan sites on the loops mapped at their approximate regions. 

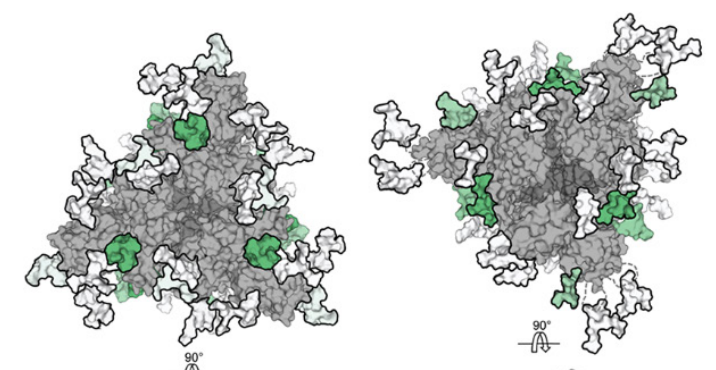

然

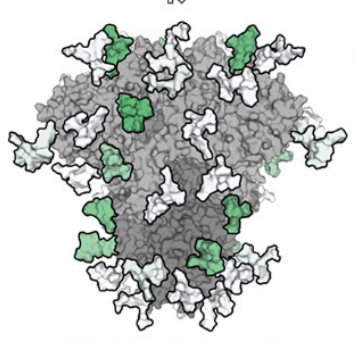

SARS-CoV-1S

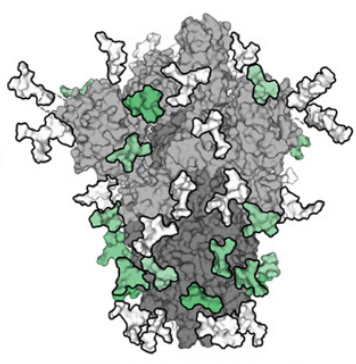

SARS-CoV-2 S

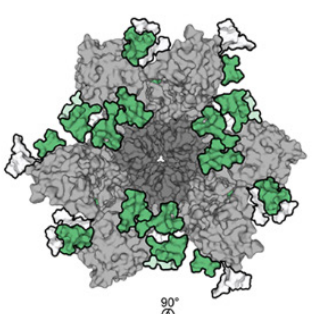

$-n^{2}$

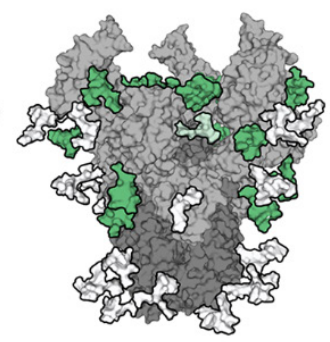

MERS COV S
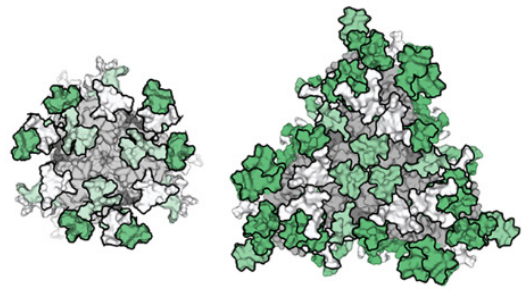

$-\mathrm{Nan}^{\circ}$

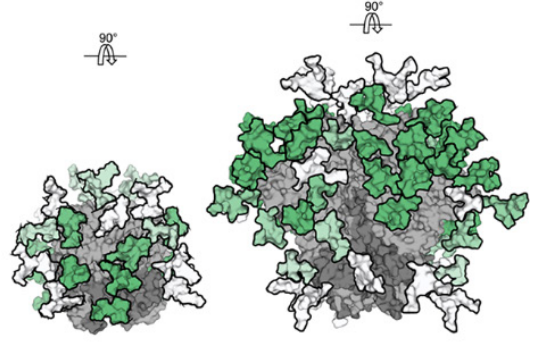

HIV-1 Env

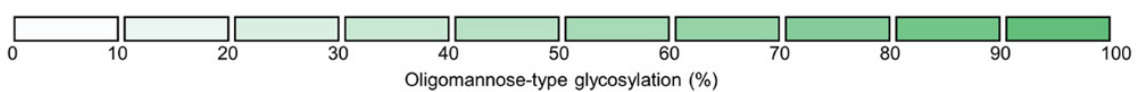

Fig. 4. Under-processing of viral glycan shields. From left to right, MERS-CoV S (10), SARS-CoV-1 S (10), SARS-CoV-2 S, LASV GPC (24), and HIV-1 Env (8, 21). Site-specific N-linked glycan oligomannose quantifications are colored according to the key. All glycoproteins were expressed as soluble trimers in HEK 293F cells apart from LASV GPC, which was derived from virus-like particles from Madin-Darby canine kidney II cells. 